\title{
Exponential type convexity and some related inequalities
}

Mahir Kadakal ${ }^{1 *}$ and Imdat İşan'

"Correspondence:

mahirkadakal@gmail.com

'Department of Mathematics,

Sciences and Arts Faculty, Giresun

University, Giresun, Turkey

\begin{abstract}
In this manuscript, we give and study the concept of exponential type convex functions and some of their algebraic properties. We prove two Hermite-Hadamard $(\mathrm{H}-\mathrm{H})$ type integral inequalities for the newly introduced class of functions. We also obtain some refinements of the $\mathrm{H}-\mathrm{H}$ inequality for functions whose first derivative in absolute value at certain power is exponential type convex.
\end{abstract}

MSC: Primary 26D15; secondary 26A51

Keywords: Convex function; Exponential type convexity; Hermite-Hadamard inequality

\section{Introduction}

A function $f: I \rightarrow \mathbb{R}$ is said to be convex function if the following inequality holds:

$$
f(k m+(1-k) n) \leq k f(m)+(1-k) f(n)
$$

for all $m, n \in I$ and $k \in[0,1]$. If (1) reverses, then $f$ is said to be concave on $I \neq \emptyset$. Convexity theory provides powerful principles and techniques for studying a class of problems in mathematics. See articles $[4,5,7,9-13]$ and the references therein.

Let $f: I \rightarrow \mathbb{R}$ be a convex function. Then the following inequalities hold:

$$
f\left(\frac{m+n}{2}\right) \leq \frac{1}{n-m} \int_{m}^{n} f(x) d x \leq \frac{f(m)+f(n)}{2}
$$

for all $m, n \in I$ with $m<n$. Inequality (2) is well known as the Hermite-Hadamard ( $\mathrm{H}-\mathrm{H})$ integral inequality [6]. Some refinements of the $\mathrm{H}-\mathrm{H}$ inequality for convex functions have been obtained $[3,15]$.

The aim of this study is to submit the concept of exponential type convex functions and find some results connected with the right-hand side of new inequalities similar to the $\mathrm{H}-\mathrm{H}$ inequality for this type of functions.

Definition 1.1 ([14]) Let $h: J \rightarrow \mathbb{R}$ be a nonnegative function and $h \neq 0$. We say that $f: I \rightarrow \mathbb{R}$ is an $h$-convex function, or that $f$ belongs to the class $S X(h, I)$, if $f$ is nonnegative

(c) The Author(s) 2020. This article is licensed under a Creative Commons Attribution 4.0 International License, which permits use, sharing, adaptation, distribution and reproduction in any medium or format, as long as you give appropriate credit to the original author(s) and the source, provide a link to the Creative Commons licence, and indicate if changes were made. The images or other third party material in this article are included in the article's Creative Commons licence, unless indicated otherwise in a credit line to the material. If material is not included in the article's Creative Commons licence and your intended use is not permitted by statutory regulation or exceeds the permitted use, you will need to obtain permission directly from the copyright holder. To view a copy of this licence, visit http://creativecommons.org/licenses/by/4.0/. 
and for all $m, n \in I, k \in[0,1]$ we have

$$
f(k m+(1-k) n) \leq h(k) f(m)+h(1-k) f(n) .
$$

If (3) is reversed, then $f$ is said to be $h$-concave, i.e., $f \in S V(h, I)$. It is clear that, if $h(u)=u$, then the $h$-convexity reduces to convexity.

Readers can look at $[1,8]$ for studies on $h$-convexity.

\section{Main results}

In this section, we give a new definition, which is called exponential type convexity, and we give it by setting some algebraic properties for the exponential type convex functions, as follows.

Definition 2.1 A nonnegative function $f: I \rightarrow \mathbb{R}$ is called exponential type convex function if, for every $m, n \in I$ and $k \in[0,1]$,

$$
f(k m+(1-k) n) \leq\left(e^{k}-1\right) f(m)+\left(e^{1-k}-1\right) f(n) .
$$

The class of all exponential type convex functions on interval $I$ is indicated by $\operatorname{EXPC}(I)$.

Remark 2.1 The range of the exponential type convex functions is $[0, \infty)$.

Proof Let $m \in I$ be arbitrary. Using the definition of the exponential type convex function for $k=1$, we have $f(m) \leq(e-1) f(m) \Longrightarrow 0 \leq(e-2) f(m) \Longrightarrow f(m) \geq 0$.

We discuss some connections between the class of exponential type convex functions and other classes of generalized convex functions.

Lemma 2.1 For all $k \in[0,1]$, the inequalities $e^{k}-1 \geq k$ and $e^{1-k}-1 \geq 1-k$ hold.

Proof The proof is obvious.

Proposition 2.1 Every nonnegative convex function is exponential type convex function.

Proof According to Lemma 2.1, since $k \leq e^{k}-1$ and $1-k \leq e^{1-k}-1$ for all $k \in[0,1]$, we obtain

$$
f(k m+(1-k) n) \leq k f(m)+(1-k) f(n) \leq\left(e^{k}-1\right) f(m)+\left(e^{1-k}-1\right) f(n) .
$$

Proposition 2.2 Every exponential type convex function is an h-convex function with $h(k)=e^{k}-1$.

Proof If we substitute $e^{k}-1=h(k)$ and $e^{1-k}-1=h(1-k)$ in inequality (3), an $h$-convex function is easily obtained.

Theorem 2.1 Let $f, g:[a, b] \rightarrow \mathbb{R}$. Iff and $g$ are exponential type convex functions, then

(i) $f+g$ is exponential type convex,

(ii) for $c \geq 0$, cf is exponential type convex. 
Proof (i) Let $f, g$ be exponential type convex, then

$$
\begin{aligned}
(f & +g)(k m+(1-k) n) \\
& =f(k m+(1-k) n)+g(k m+(1-k) n) \\
& \leq\left(e^{k}-1\right) f(m)+\left(e^{1-k}-1\right) f(n)+\left(e^{k}-1\right) g(m)+\left(e^{1-k}-1\right) g(n) \\
& =\left(e^{k}-1\right)[f(m)+g(m)]+\left(e^{1-k}-1\right)[f(n)+g(n)] \\
& =\left(e^{k}-1\right)(f+g)(m)+\left(e^{1-k}-1\right)(f+g)(n) .
\end{aligned}
$$

(ii) Let $f$ be exponential type convex and $c \in \mathbb{R}(c \geq 0)$, then

$$
\begin{aligned}
(c f)(k m+(1-k) n) & \leq c\left[\left(e^{k}-1\right) f(m)+\left(e^{1-k}-1\right) f(n)\right] \\
& =\left(e^{k}-1\right) c f(m)+\left(e^{1-k}-1\right) c f(n) \\
& =\left(e^{k}-1\right)(c f)(m)+\left(e^{1-k}-1\right)(c f)(n) .
\end{aligned}
$$

Remark 2.2 Theorem 2.1 follows from the known fact that the space of an $h$-convex function is a convex cone for each $h$ (see [14], Proposition 9).

Theorem 2.2 If $f: I \rightarrow J$ is convex and $g: J \rightarrow \mathbb{R}$ is an exponential type convex function and nondecreasing, then $g \circ f: I \rightarrow \mathbb{R}$ is an exponential type convex function.

Proof For $m, n \in I$ and $k \in[0,1]$, we get

$$
\begin{aligned}
(g \circ f)(k m+(1-k) n) & =g(f(k m+(1-k) n)) \\
& \leq g(k f(m)+(1-k) f(n)) \\
& \leq\left(e^{k}-1\right) g(f(m))+\left(e^{1-k}-1\right) g(f(n)) \\
& =\left(e^{k}-1\right)(g \circ f)(m)+\left(e^{1-k}-1\right)(g \circ f)(n) .
\end{aligned}
$$

Remark 2.3 The above theorem can also be derived from Theorem 15 in [14].

Theorem 2.3 Let $n>0$ and $f_{\alpha}:[m, n] \rightarrow \mathbb{R}$ be an arbitrary family of exponential type convex functions, and let $f(x)=\sup _{\alpha} f_{\alpha}(x)$. If $J=\{u \in[m, n]: f(u)<\infty\}$ is nonempty, then $J$ is an interval and $f$ is an exponential type convex function on $J$.

Proof Let $k \in[0,1]$ and $m, n \in J$ be arbitrary. Then

$$
\begin{aligned}
f(k m+(1-k) n) & =\sup _{\alpha} f_{\alpha}(k m+(1-k) n) \\
& \leq \sup _{\alpha}\left[\left(e^{k}-1\right) f_{\alpha}(m)+\left(e^{1-k}-1\right) f_{\alpha}(n)\right] \\
& \leq\left(e^{k}-1\right) \sup _{\alpha} f_{\alpha}(m)+\left(e^{1-k}-1\right) \sup _{\alpha} f_{\alpha}(n) \\
& =\left(e^{k}-1\right) f(m)+\left(e^{1-k}-1\right) f(n)<\infty .
\end{aligned}
$$

This shows simultaneously that $J$ is an interval, since it contains every point between any two of its points, and that $f$ is an exponential type convex function on $J$. 
Theorem 2.4 If the function $f:[m, n] \rightarrow \mathbb{R}$ is exponential type convex, then $f$ is bounded on $[m, n]$.

Proof Let $K=\max \{f(m), f(n)\}$ and $x \in[m, n]$ be an arbitrary point. Then there exists $k \in$ $[0,1]$ such that $x=k m+(1-k) n$. Thus, since $e^{k} \leq e$ and $e^{1-k} \leq e$, we have

$$
\begin{aligned}
f(x) & \leq f(k m+(1-k) n) \\
& \leq\left(e^{k}-1\right) f(m)+\left(e^{1-k}-1\right) f(n) \\
& \leq\left(e^{k}+e^{1-k}-2\right) \cdot K \\
& \leq 2(e-1) \cdot K=M .
\end{aligned}
$$

Also, for every $x \in[m, n]$, there exists $\lambda \in\left[0, \frac{n-m}{2}\right]$ such that $x=\frac{m+n}{2}+\lambda$ or $x=\frac{m+n}{2}-\lambda$. Without loss of generality, we suppose $x=\frac{m+n}{2}+\lambda$. So, we have

$$
\begin{aligned}
f\left(\frac{m+n}{2}\right) & =f\left(\frac{1}{2}\left[\frac{m+n}{2}+\lambda\right]+\frac{1}{2}\left[\frac{m+n}{2}-\lambda\right]\right) \\
& \leq(\sqrt{e}-1)\left(f(x)+f\left(\frac{m+n}{2}-\lambda\right)\right) .
\end{aligned}
$$

By using $M$ as the upper bound, we get

$$
\begin{aligned}
f(x) & \geq f\left(\frac{m+n}{2}\right) \frac{1}{\sqrt{e}-1}-f\left(\frac{m+n}{2}-\lambda\right) \\
& \geq \frac{1}{\sqrt{e}-1} f\left(\frac{m+n}{2}\right)-M=m .
\end{aligned}
$$

\section{Hermite-Hadamard inequality for exponential type convex functions}

The aim of this section is to find some inequalities of $\mathrm{H}-\mathrm{H}$ type for exponential type convex functions. In the next sections, we denote by $L[m, n]$ the space of (Lebesgue) integrable functions on the interval $[m, n]$.

Theorem 3.1 Let $f:[m, n] \rightarrow \mathbb{R}$ be an exponential type convex function. If $m<n$ and $f \in L[m, n]$, then the following Hermite-Hadamard type inequalities hold:

$$
\frac{1}{2(\sqrt{e}-1)} f\left(\frac{m+n}{2}\right) \leq \frac{1}{n-m} \int_{m}^{n} f(x) d x \leq(e-2)[f(m)+f(n)] .
$$

Proof Firstly, from the property of the exponential type convex function of $f$, we get

$$
\begin{aligned}
f\left(\frac{m+n}{2}\right) & =f\left(\frac{[k m+(1-k) n]+[(1-k) m+k n]}{2}\right) \\
& =f\left(\frac{1}{2}[k m+(1-k) n]+\frac{1}{2}[(1-k) m+k n]\right) \\
& \leq\left(e^{\frac{1}{2}}-1\right) f(k m+(1-k) n)+\left(e^{1-\frac{1}{2}}-1\right) f((1-k) m+k n) .
\end{aligned}
$$


Now, if we take integral in the last inequality with respect to $k \in[0,1]$, we deduce that

$$
\begin{aligned}
& f\left(\frac{m+n}{2}\right) \\
& \quad \leq\left[\left(e^{\frac{1}{2}}-1\right) \int_{0}^{1} f(k m+(1-k) n) d k+\left(e^{\frac{1}{2}}-1\right) \int_{0}^{1} f((1-k) m+k n) d k\right] \\
& \quad=\frac{2(\sqrt{e}-1)}{n-m} \int_{m}^{n} f(x) d x .
\end{aligned}
$$

Secondly, by using the property of the exponential type convex function $f$, if the variable is changed as $u=k m+(1-k) n$, then

$$
\begin{aligned}
\frac{1}{n-m} \int_{m}^{n} f(u) d u & =\int_{0}^{1} f(k m+(1-k) n) d k \\
& \leq \int_{0}^{1}\left\{\left(e^{k}-1\right) f(m)+\left(e^{1-k}-1\right) f(n)\right\} d k \\
& =(e-2)[f(m)+f(n)] .
\end{aligned}
$$

\section{Some new inequalities for exponential type convex functions}

The aim of this section is to find new estimates that refine $\mathrm{H}-\mathrm{H}$ inequality for functions whose first derivative in absolute value at certain power is exponential type convex. Dragomir and Agarwal [2] used the following lemma.

Lemma 4.1 ([2]) Let $f: I^{\circ} \subseteq \mathbb{R} \rightarrow \mathbb{R}$ be a differentiable mapping on $I^{\circ}, m, n \in I^{\circ}$ with $m<n$. If $f^{\prime} \in L[m, n]$, then the following identity holds:

$$
\frac{f(m)+f(n)}{2}-\frac{1}{n-m} \int_{m}^{n} f(x) d x=\frac{n-m}{2} \int_{0}^{1}(1-2 k) f^{\prime}(k m+(1-k) n) d k .
$$

Theorem 4.1 Let $f: I \rightarrow \mathbb{R}$ be a differentiable function on $I^{\circ}, m, n \in I^{\circ}$ with $m<n$, and assume that $f^{\prime} \in L[m, n]$. If $\left|f^{\prime}\right|$ is an exponential type convex function on $[m, n]$, then the inequality

$$
\left|\frac{f(m)+f(n)}{2}-\frac{1}{n-m} \int_{m}^{n} f(x) d x\right| \leq(n-m)\left(4 \sqrt{e}-e-\frac{7}{2}\right) A\left(\left|f^{\prime}(m)\right|,\left|f^{\prime}(n)\right|\right)
$$

holds for $k \in[0,1]$, where $A(u, v)$ is the arithmetic mean of $u$ and $v$.

Proof From Lemma 4.1 and the inequality

$$
\left|f^{\prime}(k m+(1-k) n)\right| \leq\left(e^{k}-1\right)\left|f^{\prime}(m)\right|+\left(e^{1-k}-1\right)\left|f^{\prime}(n)\right|
$$

we get

$$
\begin{aligned}
& \left|\frac{f(m)+f(n)}{2}-\frac{1}{n-m} \int_{m}^{n} f(x) d x\right| \\
& \leq \frac{n-m}{2} \int_{0}^{1}|1-2 k|\left|f^{\prime}(k m+(1-k) n)\right| d k
\end{aligned}
$$




$$
\begin{aligned}
& \leq \frac{n-m}{2} \int_{0}^{1}|1-2 k|\left[\left(e^{k}-1\right)\left|f^{\prime}(m)\right|+\left(e^{1-k}-1\right)\left|f^{\prime}(n)\right|\right] d k \\
& =\frac{n-m}{2}\left[\left|f^{\prime}(m)\right| \int_{0}^{1}|1-2 k|\left(e^{k}-1\right) d k+\left|f^{\prime}(n)\right| \int_{0}^{1}|1-2 k|\left(e^{1-k}-1\right) d k\right] \\
& =(n-m)\left(4 \sqrt{e}-e-\frac{7}{2}\right) A\left(\left|f^{\prime}(m)\right|,\left|f^{\prime}(n)\right|\right)
\end{aligned}
$$

where

$$
\int_{0}^{1}|1-2 k|\left(e^{k}-1\right) d k=\int_{0}^{1}|1-2 k|\left(e^{1-k}-1\right) d k=4 \sqrt{e}-e-\frac{7}{2} .
$$

Theorem 4.2 Let $f: I \rightarrow \mathbb{R}$ be a differentiable function on $I^{\circ}, m, n \in I^{\circ}$ with $m<n, q>1$, and assume that $f^{\prime} \in L[m, n]$. If $\left|f^{\prime}\right|^{q}$ is an exponential type convex function on $[m, n]$, then the inequality

$$
\left|\frac{f(m)+f(n)}{2}-\frac{1}{n-m} \int_{m}^{n} f(x) d x\right| \leq \frac{n-m}{2}[2(e-2)]^{\frac{1}{q}}\left(\frac{1}{p+1}\right)^{\frac{1}{p}} A^{\frac{1}{q}}\left(\left|f^{\prime}(m)\right|^{q},\left|f^{\prime}(n)\right|^{q}\right)
$$

holds for $k \in[0,1]$, where $\frac{1}{p}+\frac{1}{q}=1$ and $A$ is the arithmetic mean.

Proof From Lemma 4.1, Hölder's integral inequality, and the following inequality:

$$
\left|f^{\prime}(k m+(1-k) n)\right|^{q} \leq\left(e^{k}-1\right)\left|f^{\prime}(m)\right|^{q}+\left(e^{1-k}-1\right)\left|f^{\prime}(n)\right|^{q}
$$

which is the exponential type convex function of $\left|f^{\prime}\right|^{q}$, we get

$$
\begin{aligned}
& \left|\frac{f(m)+f(n)}{2}-\frac{1}{n-m} \int_{m}^{n} f(x) d x\right| \\
& \quad \leq \frac{n-m}{2} \int_{0}^{1}|1-2 k|\left|f^{\prime}(k m+(1-k) n)\right| d k \\
& \quad \leq \frac{n-m}{2}\left(\int_{0}^{1}|1-2 k|^{p} d k\right)^{\frac{1}{p}}\left(\int_{0}^{1}\left|f^{\prime}(k m+(1-k) n)\right|^{q} d k\right)^{\frac{1}{q}} \\
& \quad \leq \frac{n-m}{2}\left(\frac{1}{p+1}\right)^{\frac{1}{p}}\left(\int_{0}^{1}\left[\left(e^{k}-1\right)\left|f^{\prime}(m)\right|^{q}+\left(e^{1-k}-1\right)\left|f^{\prime}(n)\right|^{q}\right] d k\right)^{\frac{1}{q}} \\
& \quad=\frac{n-m}{2}[2(e-2)]^{\frac{1}{q}}\left(\frac{1}{p+1}\right)^{\frac{1}{p}} A^{\frac{1}{q}}\left(\left|f^{\prime}(m)\right|^{q},\left|f^{\prime}(n)\right|^{q}\right) .
\end{aligned}
$$

Theorem 4.3 Let $f: I \rightarrow \mathbb{R}$ be a differentiable function on $I^{\circ}, m, n \in I^{\circ}$ with $m<n, q \geq 1$, and assume that $f^{\prime} \in L[m, n]$. If $\left|f^{\prime}\right|^{q}$ is an exponential type convex function on $[m, n]$, then the inequality

$$
\begin{aligned}
& \left|\frac{f(m)+f(n)}{2}-\frac{1}{n-m} \int_{m}^{n} f(x) d x\right| \\
& \leq \frac{n-m}{2^{2-\frac{1}{q}}}\left[2\left(4 \sqrt{e}-e-\frac{7}{2}\right)\right]^{\frac{1}{q}} A^{\frac{1}{q}}\left(\left|f^{\prime}(m)\right|^{q},\left|f^{\prime}(n)\right|^{q}\right)
\end{aligned}
$$

holds for $k \in[0,1]$. 
Proof Assume first that $q>1$. By using Lemma 4.1, Hölder's inequality, and the property of the exponential type convex function of $\left|f^{\prime}\right|^{q}$, we obtain

$$
\begin{aligned}
& \left|\frac{f(m)+f(n)}{2}-\frac{1}{n-m} \int_{m}^{n} f(x) d x\right| \\
& \quad \leq \frac{n-m}{2} \int_{0}^{1}|1-2 k|\left|f^{\prime}(k m+(1-k) n)\right| d k \\
& \quad \leq \frac{n-m}{2}\left(\int_{0}^{1}|1-2 k| d k\right)^{1-\frac{1}{q}}\left(\int_{0}^{1}|1-2 k|\left|f^{\prime}(k m+(1-k) n)\right|^{q} d k\right)^{\frac{1}{q}} \\
& \quad=\frac{n-m}{2}\left(\frac{1}{2}\right)^{1-\frac{1}{q}}\left(\int_{0}^{1}|1-2 k|\left[\left(e^{k}-1\right)\left|f^{\prime}(m)\right|^{q}+\left(e^{1-k}-1\right)\left|f^{\prime}(n)\right|^{q}\right] d k\right)^{\frac{1}{q}} \\
& \quad=\frac{n-m}{2^{2-\frac{1}{q}}}\left[2\left(4 \sqrt{e}-e-\frac{7}{2}\right)\right]^{\frac{1}{q}} A^{\frac{1}{q}}\left(\left|f^{\prime}(m)\right|^{q},\left|f^{\prime}(n)\right|^{q}\right) .
\end{aligned}
$$

For $q=1$, we consider the estimates from the proof of Theorem 4.1, which also follows step by step the above estimates.

Remark 4.1 Under the assumptions of Theorem 4.3 with $q=1$, we get the conclusion of Theorem 4.1.

\section{Applications for special means}

Throughout this section, for the sake of simplicity, the following notations are used for special means of two nonnegative numbers $m, n(n>m)$ :

1. The arithmetic mean

$$
A:=A(m, n)=\frac{m+n}{2}, \quad m, n \geq 0
$$

2. The geometric mean

$$
G:=G(m, n)=\sqrt{m n}, \quad m, n \geq 0
$$

3. The harmonic mean

$$
H:=H(m, n)=\frac{2 m n}{m+n}, \quad m, n>0 .
$$

4. The logarithmic mean

$$
L:=L(m, n)= \begin{cases}\frac{n-m}{\ln n-\ln m}, & m \neq n, \\ m, & m=n ; \quad m, n>0 .\end{cases}
$$

5. The $p$-logarithmic mean

$$
L_{p}:=L_{p}(m, n)=\left\{\begin{array}{ll}
\left(\frac{n^{p+1}-m^{p+1}}{(p+1)(n-m)}\right)^{\frac{1}{p}}, & m \neq n, p \in \mathbb{R} \backslash\{-1,0\}, \\
m, & m=n ;
\end{array} \quad m, n>0 .\right.
$$


6. The identric mean

$$
I:=I(m, n)=\frac{1}{e}\left(\frac{n^{n}}{m^{m}}\right)^{\frac{1}{n-m}}, \quad m, n>0 .
$$

It is well known that $L_{p}$ is monotonically increasing over $p \in \mathbb{R}$. Moreover, $L_{0}=I, L_{-1}=L$.

Proposition 5.1 Let $m, n \in[0, \infty)$ with $m<n$ and $r \in(-\infty, 0) \cup[1, \infty) \backslash\{-1\}$. Then the inequalities

$$
\frac{A^{r}(m, n)}{2(\sqrt{e}-1)} \leq L_{r}^{r}(m, n) \leq 2(e-2) A\left(m^{r}, n^{r}\right)
$$

hold.

Proof It is easily seen from inequalities (5) for the function

$$
f(x)=x^{r}, \quad x \in[0, \infty)
$$

Proposition 5.2 Let $m, n \in(0, \infty)$ with $m<n$. Then the inequalities

$$
\frac{A^{-1}(m, n)}{2(\sqrt{e}-1)} \leq L^{-1}(m, n) \leq 2(e-2) H^{-1}(m, n)
$$

hold.

Proof It is easily seen from inequalities (5) for the function

$$
f(x)=x^{-1}, \quad x \in(0, \infty) .
$$

Proposition 5.3 Let $m, n \in(0,1]$ with $m<n$. Then the inequalities

$$
2(e-2) \ln G(m, n) \leq \ln I(m, n) \leq \frac{\ln A(m, n)}{2(\sqrt{e}-1)}
$$

hold.

Proof It is easily seen from inequalities (5) for the function

$$
f(x)=-\ln x, \quad x \in(0,1]
$$

\section{Conclusion}

In this paper, we studied the concept of exponential type convex functions, which is a new concept. We proved some new Hermite-Hadamard type integral inequalities for the newly introduced class of functions using an identity together with Hölder's integral inequality. Especially, we would like to emphasize that different types of integral inequalities can be obtained using this new definition. 
Funding

There is no funding for this work.

\section{Abbreviations}

Not applicable.

Availability of data and materials

Not applicable.

Competing interests

The authors declare that they have no competing interests.

\section{Authors' contributions}

The authors read and approved the final manuscript.

\section{Publisher's Note}

Springer Nature remains neutral with regard to jurisdictional claims in published maps and institutional affiliations.

Received: 20 December 2019 Accepted: 18 March 2020 Published online: 30 March 2020

\section{References}

1. Bombardelli, M., Varošanec, S.: Properties of $h$-convex functions related to the Hermite-Hadamard-Fejér inequalities. Comput. Math. Appl. 58, 1869-1877 (2009)

2. Dragomir, S.S., Agarwal, R.P.: Two inequalities for differentiable mappings and applications to special means of real numbers and to trapezoidal formula. Appl. Math. Lett. 11, 91-95 (1998)

3. Dragomir, S.S., Pearce, C.E.M.: Selected Topics on Hermite-Hadamard Inequalities and Its Applications. RGMIA Monograph (2002)

4. Dragomir, S.S., Pečarić, J., Persson, L.E.: Some inequalities of Hadamard type. Soochow J. Math. 21(3), 335-341 (2001)

5. Guessab, A., Schmeisser, G.: Sharp integral inequalities of the Hermite-Hadamard type. J. Approx. Theory 115(2), 260-288 (2002)

6. Hadamard, J.: Étude sur les propriétés des fonctions entières en particulier d'une fonction considérée par Riemann. J. Math. Pures Appl. 58, 171-215 (1893)

7. İşcan, I., Kunt, M.: Hermite-Hadamard-Fejer type inequalities for quasi-geometrically convex functions via fractional integrals. J. Math. 2016, Article ID 6523041 (2016)

8. Kadakal, H.: Hermite-Hadamard type inequalities for trigonometrically convex functions. Sci. Stud. Res. Ser. Math. Inform. 28(2), 19-28 (2018)

9. Kadakal, H.: New inequalities for strongly $r$-convex functions. J. Funct. Spaces 2019, Article ID 1219237 (2019)

10. Kadakal, H., Kadakal, M., İscan, I.: Some new integral inequalities for $n$-times differentiable $s$-convex functions in the first sense. Turk. J. Anal. Number Theory 5(2), 63-68 (2017)

11. Maden, S., Kadakal, H., Kadakal, M., Işcan, I.: Some new integral inequalities for $n$-times differentiable convex and concave functions. J. Nonlinear Sci. Appl. 10(12), 6141-6148 (2017)

12. Özcan, S.: Some integral inequalities for harmonically $(\alpha, s)$-convex functions. J. Funct. Spaces 2019, Article ID 2394021 (2019)

13. Özcan, S., İşcan, l.: Some new Hermite-Hadamard type inequalities for s-convex functions and their applications. J. Inequal. Appl. 2019, Article ID 201 (2019)

14. Varošanec, S.: On h-convexity. J. Math. Anal. Appl. 326, 303-311 (2007)

15. Zabandan, G.: A new refinement of the Hermite-Hadamard inequality for convex functions. J. Inequal. Pure Appl. Math. 10(2), Article ID 45 (2009)

\section{Submit your manuscript to a SpringerOpen ${ }^{\circ}$ journal and benefit from:}

- Convenient online submission

- Rigorous peer review

- Open access: articles freely available online

- High visibility within the field

- Retaining the copyright to your article

Submit your next manuscript at $\gg$ springeropen.com 